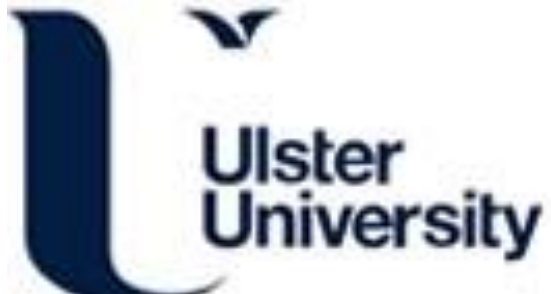

\section{Ambient Interface Design (AID) for the Ergonomically Challenged}

Hegarty, R., Lunney, T., Curran, K., \& Mulvenna, M. (2010). Ambient Interface Design (AID) for the Ergonomically Challenged. International Journal of Ambient Computing and Intelligence, 2(2), 57-64. https://doi.org/10.4018/jaci.2010040104

Link to publication record in Ulster University Research Portal

\section{Published in:}

International Journal of Ambient Computing and Intelligence

\section{Publication Status:}

Published (in print/issue): 01/04/2010

DOI:

10.4018/jaci.2010040104

\section{Document Version}

Author Accepted version

\section{General rights}

Copyright for the publications made accessible via Ulster University's Research Portal is retained by the author(s) and / or other copyright owners and it is a condition of accessing these publications that users recognise and abide by the legal requirements associated with these rights.

\section{Take down policy}

The Research Portal is Ulster University's institutional repository that provides access to Ulster's research outputs. Every effort has been made to ensure that content in the Research Portal does not infringe any person's rights, or applicable UK laws. If you discover content in the Research Portal that you believe breaches copyright or violates any law, please contact pure-support@ulster.ac.uk. 


\title{
Ambient Interface Design (AID) for the Ergonomically Challenged
}

\author{
Rosaleen Hegarty, University of Ulster, Northern Ireland \\ Tom Lunney, University of Ulster, Northern Ireland \\ Kevin Curran, University of Ulster, Northern Ireland \\ Maurice Mulvenna, University of Ulster, Northern Ireland
}

\begin{abstract}
Mobile devices offer convenient communication capabilities and have the potential to create intermediary supportfor ergonomically challenged users. With the global proliferation of increasing longevity, assisting the elderly and those living with impediments through human engineering and computing technology is pivotal to biotechnological attainment. To remain independently empowered, seamless integrations through efficient affable interfaces are required to provide sedulous location-independent and appliance-sensitive media viewing for the user. The Ambient Interface Design (AID) system assists with finding personal preferences and provides a synchronisation framework, coordinating connectivity across various environmentally distributed devices via sensor data mapping. Cooperative interface communication coupled with context awareness will be abstracted to a representation that facilitates optimisation and customisation to these displays. To overcome personal challenges in the efficient selection and acquisition of online information, AID mediates between the needs of the user and the constraints of the technology to provide a singular customised encapsulation of 'ability preference and device'for each authenticated member. A particular emphasis is the application of a human-centered design ethos.
\end{abstract}

Keywords: $\quad$ Ability-Based User Interfaces, Ambient Intelligence (Aml), Ergonomically Challenged, Human Computer Interaction, Psychology

\section{INTRODUCTION}

Ambient Intelligence (AmI) seeks to provide seamless integration of technologies to support a ubiquitous yet pervasive transparent framework for the implementation of electronic assistive

DOI: $10.4018 /$ jaci.2010040104 environments. These 'smart', utilitarian electronic spaces are perceptive and responsive to the presence of an individual or individuals within a context domain (Aarts, 2005). Home, work and educational environments built on the ambient intelligence paradigm will offer flexible functionality through ubiquitous embedded computing facilitated by means of wireless

Copyright (C) 2010, IGI Global. Copying or distributing in print or electronic forms without written permission of IGI Global is prohibited. 
communication and robust ad hoc networks. Smart behaviour associated with the technology is its ability to detect events, triggered by user actions within a designated milieu and to respond in an intelligent acceptable way to provide duteous 'virtual services' for that user. AmI utilises multi-disciplinary approaches to enhance greater human technology communication through distributed intelligence, data and information communication and amongst other disciplines it incorporates social science, psychology, ethics and law (Remagnino \& Foresti, 2005). Moving the user to the foreground has acute legal and ethical implications that should be reflected in the design theory (Remagnino $\&$ Foresti, 2005). Personalisation of the user provides for adaptive and anticipatory utility within the ergonomics of the system.

The objective of this study concentrates on user ergonomics through the development of a system that incorporates multiple display devices in the development of an Ambient Interface Design (AID) for the ergonomically challenged. The purpose of which is for user convenience in multiple settings in overcoming challenges met by those wishing to remain independent and living with disability through aging; hence a comfortable and productive environment is created.

Through the use of wireless network technologies advanced mobile communication will be enabled with sensor components such as Radio Frequency Identification (RFID) readings to activate AID in a new context. AID will sanction the 'firing up' of Internet sessions on a selected device tailored to a user's ability and preference, and continue with the seamless coalescence and switching to other appliances whilst perpetuating a constant session browsing experience for the user.

This is achieved by caching the mobile web session and associated objects and relaying them to another possibly central repository, to facilitate viewing to commence as a new 'continued' session on a different platform. Personal Computers (PCs), Flat screens, smart mobile phones, and Personal Digital Assistants
(PDAs) are proposed for this implementation encompassing sensor technology in ambient space supported by wireless networks over distributed locations.

Thus the new session is permitted by utilising user audience preference or by identifying user movement from within an edifice and incorporating the information held in a database on each individual user regarding ability and preference. The 'continued'session will display the terminating screen of the previous device as the launch screen for the new contrivance hence permitting persistent successive viewing for the user enabling Internet mobility with successful ergonomics.

\section{Motivation for AID}

Ambient Intelligence (AmI) summons an imperative paradigmatic shift in social networking and computing systems. The human centered approach characterises a new direction in computing technology to "augment consciousness" (de Man, 2003) and accommodate humanmachine co-operation (van Loenen, 2003). The emphasis is on efficient user affable and immersive interfaces with distributed virtual services that surround; empowering the user with control (Ducatel, Bogdanowicz, Scapolo, Leijten, \& Burgelman, 2001; Cassens \& KofodPetersen, 2007).

By embedding computational intelligence into the network and relocating the user to the foreground, this permutation will occur (Aarts, 2005). Supporting the users' presence with anticipated intuitive perceptive interactions, the modification will be apparent; thus the user becomes the focus, and no longer the technology.

AmI is a "novel anthropomorphic humanmachine model of interaction" creating synergies between the user and the environment (Remagnino \& Foresti, 2005). The vision for AmI is to permeate society operating omnipresently, non-intrusively and transparently. It is in the application of ascribing human characteristics such as sensory perception and cognitive behavioural interaction correlating to events,

Copyright (C 2010, IGI Global. Copying or distributing in print or electronic forms without written permission of IGI Global is prohibited. 
responses and user profiling in the machine model to physical or hidden measures such as embedded devices and wireless networks that the essence of ambient intelligence is encapsulated to provide user proficiency (Ishii, 2008) and enhanced human technology accomodation.

As a consequence of our mobile online international information infrastructure, modern society citizenship is becoming that of 'dual personality' combining both the digital and physical citizen in tomorrow's world (Ishii \& Ullmer, 1997). The Internet has radically infiltrated society, influencing information exchange and consummation. It's depth of features extends to, interactive blog content with the shift change from traditional broadcast to YouTube video and tagged repositories such as Flickr and Facebook(Lopez-de-Ipina, Vazquez, \& Abaitua, 2007).

Web Organisations such as Google, Yahoo, $\mathrm{AOL}$ and Microsoft are offering diverse functionality in the form of media-news, images, maps and advertisements. Internet technology has the potential to abet social exclusion and provide social interaction for society. Evidence of this phenomenon is most apparent amongst our youth culture (Lopez-de-Ipina, Vazquez, \& Abaitua, 2007), as most forms of social interaction are extended via text, Bibo, Flickr, and Facebook amongst others. This implies optimisation of information exchange in the future and not restricted to 'youth culture'.

Despite current practices of Internet access such as the keyboard and mouse combination; it is generally accepted that these interactions fall short of natural communication and has the potential to exclude enfeebled citizens. Thus by introducing sensor activity in the environment and possibly on the user, interactions with technology has the potential to become more natural and intuitive in nature. The constant focus is on "pervasive and not invasive" for user convenience (Punie, 2003).

\section{The Focus Group for AID}

Technological advancement is an active area of research today with particular emphasis on members living with disability and cognitive dysfunction in a population aging society (Jorge, 2001; Dong, Keates, \& Clarkson, 2002; Tham, 1998). In maintaining autonomy and social independence for these individuals whilst improving self-efficacy, individualism becomes a key element in the design process (Newell, 2008; Warschauer, 2004; Stanford Encyclopedia of Philosophy, 2009). This group's requirements are heterogeneous (Hawthorn, 2000); therefore enabling the provision of equality in overcoming some disability and without discrimination on ethnicity, background or technical illiteracy makes this a multi-faceted task at a user sensitive design stage.

By providing for minority groups such as those living with disability often in a serendipitous manner leads to better functionality for all. Evidence of this is demonstrated by the text predication systems used in mobile phones. Text predication was originally developed for those with physical disabilities unable to use the standard QWERTY keyboard, and this led to adaptive and predictive interfaces found today on all handheld text messaging telecommunication devices (Newell, 2008). These and similar challenges have stretched the design process to explore novel methods in overcoming the question of using personal interface real estate in an optimum way.

\section{INTERFACE DESIGN}

Too often interfaces were designed with the presumption that they will be the tools of able bodied users with high level cognitive and perceptual capabilities (Gajos, 2008). Interfaces should be adaptable to meet the needs and reflect the context of respective users over multiple mobile and stationary heterogeneous devices, which is the objective of this research in creating successful ergonomics in ambient space. These heterogeneous devices include PDAs, PCs, Smart phones, Flat screens and Laptops facilitating the mobility and flexibility that is the underlying premise of Information and Communication Technology (ICT). 
The intention is to adapt applications and interfaces to user preferences and in so doing increase efficiency and ease of use when moving between each to complete a task such as an online reservation. This sense of fluidity promotes achievement and reduces stress in permitting the user to fulfil a task with increased flexibility without a requirement to re-authenticate as all information is cached and retrieved from the last available page to the new display device. Individual requirements suggests a prerequisite for 'Personalised Interfaces', mediating between the needs of the user and the technology hence overcoming individual capabilities, preferences and tasks to enhance satisfaction, speed, and performance (Gajos, Weld, \& Wobbrock, 2008).

\section{Ambient Intelligent Interfaces}

Ambient Intelligence has indeed brought a new perspective to the psychology of Human Computer Interaction. The technology is no longer the focus; rather the user becomes central through a physical and digital co-existence (Remagnino \& Foresti, 2005). Carbonell reflects on ambient interface interactions as having to be reconfigured for throughput to output terminals of varying media and screen dimensions (Carbonell, 2006). Implementation of these constraints gives rise to 'interface plasticity' and 'adaptive multimodality' (Calvary, Thevenin, \& Coutaz, 2003). However maintaining simplicity whilst asserting notions of 'calm' remains the consummation in these phenomena and a reflection of the technology we seek in providing ergonomics.

This anthropomorphic model of distributed cognition between media and man has co-existed and evolved from cave paintings embodying spiritual expression and social interaction through to today's smart technology; with implications for increased social convergent media-creating synergies between the user and the environment (Lugmayr, Risse, Stockleben, Kaario, \& Laurila, 2008). It is an observation that mobile devices despite their technological image are in fact socially driven communica- tion tools utilising the Web (Lugmayr, Risse, Stockleben, Kaario, \& Laurila, 2008).

\section{DESIGN PRINCIPLES}

The intention of this research is to provide a synchronisation framework that will provide co-ordinated connectivity across various environmentally distributed devices via sensor data mapping and tracking to provide locationindependent and application-responsive screening for the personalised user experience. This ergonomic system may be placed within a user's home or social care establishment. The AID system's main function is the autonomous realisation of a user's presence via Radio Frequency IDentification-RFID supported readings with the aim of delivering contextual personal user preference interfaces permitting implicit and explicit interaction within a dynamic system.

Based on the Supple toolkit (Gajos, 2008; Gajos, Weld, \& Wobbrock, 2008) application, which implements 'decision-theoretic optimization' in automatically generating user interfaces; we will implement a Grails web based Java framework that will utilise a database for authentication, preference elicitation, and interface optimisation and customisation. This information will be used to optimise user preferences at run time over all currently connected device displays. The AID system (Figure 1) will take as input the preference elicitation information along with the associated device constraints and customise the interface accordingly.

Contextualised content viewing is required for the automated provision of services based on the users profile and preference. Adaptability to a user's situation is enabled by context awareness, "Context is any information that can be used to characterise a situation of an entity" (Schmidt, 2005). This entity can be a person, place or computational device, alternatively has real existence and can change dynamically. Schmidt et al., say "context can give meaning to something else (Schmidt, 2005). The sources available to contextual information 


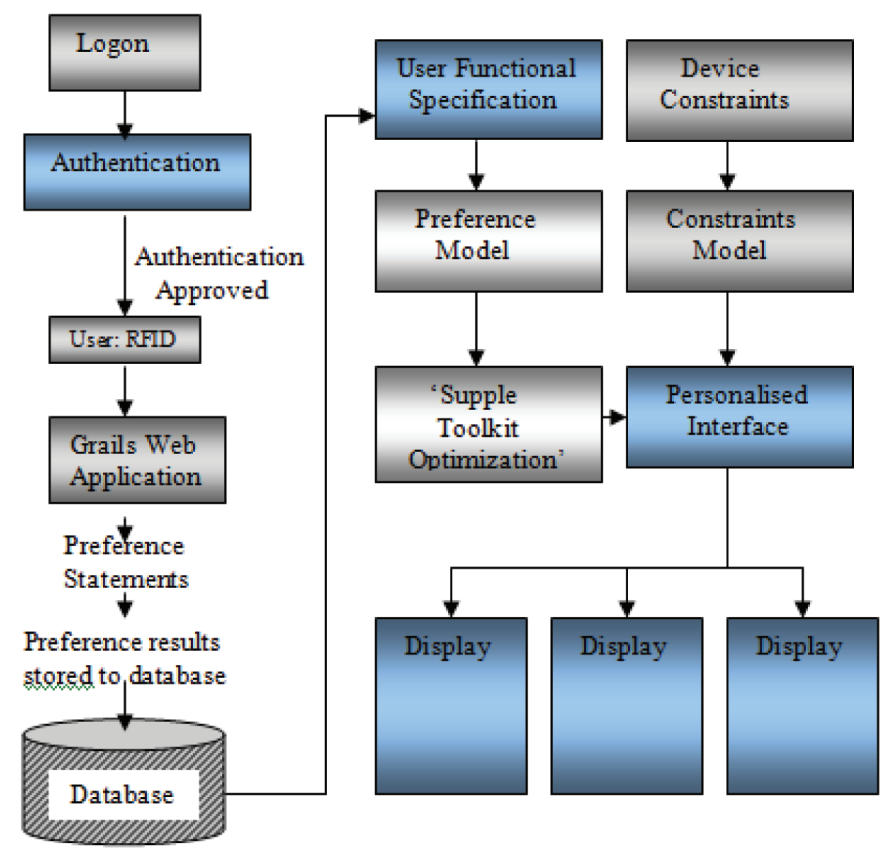

in this research include sensors in mobile devices, RFID tags, network servers and application servers among others. Generally context will refer to the identification of users, tasks and their objectives and exploited and adapted by the system.

This communication will permit a many to many (n:n) exchange via shared distributed devices utilised in smart architectural space enabling the creation of surround and fluid protean displays, as illustrated in Figure 2.

A one too many $(1: n)$ configuration is substantiated when a user's tag reading whilst dynamically adapting to user requirements through reconfiguration, 'trust,' 'security' and 'safety' standards must also be adhered to, and integrated into the system design. The core of the application architecture is to provide natural interactions and abstraction of the underlying technical communication infrastructure; hiding complexity, whilst enhancing experience and confidence. Successful ubiquity however, requires transparency integrated into the ecology of one's environment facilitated through peripheral interfacing.

Figure 2. 1:n Interface integration across heterogeneous devices

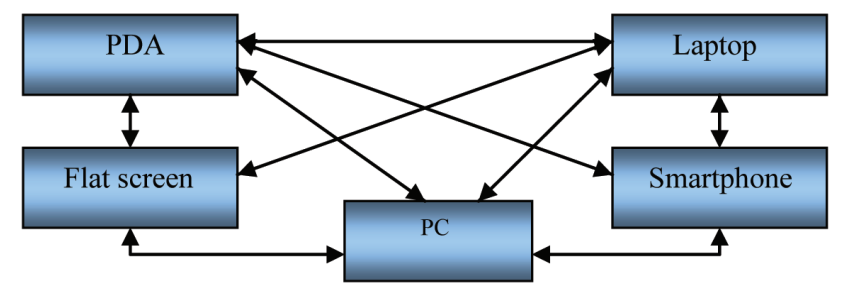

Copyright (C) 2010, IGI Global. Copying or distributing in print or electronic forms without written permission of IGI Global is prohibited. 
The key components of AID work to ensure continuity of service between multiple parts and include a sensor network, web server, session server, and user session (to store user history, cookies, current web page state and bookmarks amongst other user facilities) to different displays. The server side can act as a coordinator to manage the data, and facilitate screen resizing before exporting to a newly activated device. The client side component will have the necessary functionality to manage session synchronisation as a feature. The server must also maintain a user's personal profile and orchestrate this profile to heterogeneous devices within dynamic environments. In addition the server will also be responsible for carrying out routine authentication and authorisation and provide session state and mobility handling within the system.

Communication within the AID system will be server controlled, with clients communicating through the server (Figure 3). There will be instances where a single client to server communication will occur as in authentication, and device discovery within the network and indeed server to client communication. A client to server to client instance whereby the client can cause the server to affect another client, and also a client to client where data can transfer from one client to another directed by the server.

\section{CONCLUSION}

Technologically integrated spaces will change our perception of information and our behav- ioural interactions associated with its provision. The main aim in this proposed system is to deliver contextual user preferences without the need for direct user manipulation in overcoming age or disability related issues in providing for ergonomics. In recognising individual capabilities and needs an enhancement of satisfaction, speed and performance should be experienced. Ubiquity and seamless access through Internet services will assist in providing adaptive personal interfaces in mixed mode modality and media. Proactive collaboration between the possible devices aims to capture and simplify tasks for the elderly and those with disability in a sensitive, secure and intuitive environment endorsing efficient support in tailoring to the user requirements.

This will help to ensure seamless continuity between components providing usability and maximum user convenience. AID will as a prerequisite for 'Personalised Interfaces', aim to mediate between the needs of the user and the technology to help reduce personal challenges and provide a customised user experience for the efficient selection and acquisition of online information customised to preference, ability and chosen device.

In so doing a mobile persistent browsing experience will be filtered to the user as they roam un-tethered keeping data and communications ubiquitous. Citizens on the move are becoming networks on the move as individuals carrying devices are integrated into a framework of networks supporting a dynamic experience (EISTP, 2004; Filipe \& Mamede, 2005).

Figure 3. (a) Clients (devices) communicate with the server and vice versa, (b) client to server to client instance and (c) client to client directed by the server

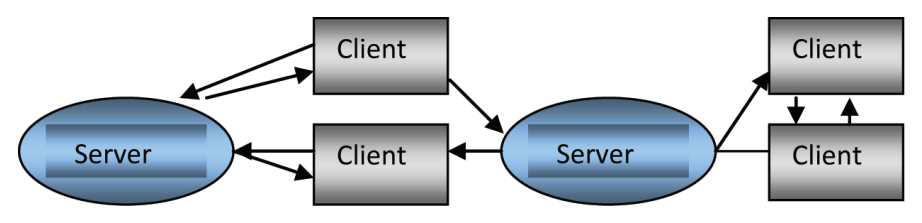

Copyright (C) 2010, IGI Global. Copying or distributing in print or electronic forms without written permission of IGI Global is prohibited. 


\section{REFERENCES}

Aarts, E. (2005). Foreword . In Cai, Y., \& Abascal, J. (Eds.), Ambient Intelligence in Everyday Life State of the Art Survey (p. vii). New York: Springer.

Cai, Y. (2007). Instinctive Computing. In M. Pantic (Eds.), Human Computing (LNAI 4451). New York: Springer.

Calvary, G., Thevenin, D., \& Coutaz, J. (2003). A Reference Framework for the Development of Plastic User Interfaces. Retrieved June 20, 2008, from http:// iihm.imag.fr/publs/2003/MuiBook03.pdf

Carbonell, N. (2006). Ambient Multimodality: towards Advancing Computer Accessibility and Assisted Living. International Journal on Universal Access in the Information Society (UAIS), 18-26.

Cassens, J., \& Kofod-Petersen, A. (2007). Explanations and Case-Based Reasoning in Ambient Intelligent Systems. Retrieved November 26, 2007, from http://ceur-ws.org de Man, H. (2003). Foreword. In T. Basten, M. Geilen, \& H. de Groot (Eds.), Ambient Intelligence: Impact on Embedded System Design (p. vii). New York: Kluwer.

Dong, H., Keates, S., \& Clarkson, P. J. (2002). Accommodating older users' functional capabilities . In Brewster, S., \& Zajicek, M. (Eds.), HCI BCS London (pp. 10-11).

Ducatel, K., Bogdanowicz, M., Scapolo, F., Leijten, J., \& Burgelman, J. C. (2001). ISTAG Scenarios for Ambient Intelligence in 2010. Tech. Rep.

Filipe, P., \& Mamede, N. (2005). Towards Ubiquitous Task Management. Retrieved January 14, 2008, from http://www.inesc-id.pt/ficheiros/publicacoes/2166.pdf

Gajos, K. Z. (2008). Automatically Generating User Interfaces. Unpublished doctoral dissertation, University of Washington, Seattle, WA. Retrieved July 30, 2009, from http://www.cs.washington.edu/ ai/puirg/papers/kgajos-dissertation.pdf

Gajos, K. Z., Weld, D. S., \& Wobbrock, J. O. (2008). Decision-Theoretic User Interface Generation. In Proceedings of AAAI'08, NECTAR paper track, Chicago, IL.

Hawthorn, D. (2000). Possible implications of aging for interface designers. Interacting with Computers, 12, 507-528. doi:10.1016/S0953-5438(99)00021-1
Ishii, H. (2008). Tangible User Interfaces, MIT Media Laboratory . In Sears, A., \& Jacko, J. A. (Eds.), The human-Computer Interaction Handbook, Fundamentals, Evolving Technologies and Emerging Applications. New York: CRC Press.

Ishii, H., \& Ullmer, B. (1997). Tangible bits: Towards seamless interfaces between people, bits and atoms. In Proceedings of CHI'97 (pp. 234-241).

Jorge, J. (2001). Adaptive Tools for the Elderly. New Devices to cope with Age-Induced Cognitive Disabilities.

Lopez-de-Ipina, D., Vazquez, J. I., \& Abaitua, J. (2007). A Web 2.0 Platform to Enable Context-Aware Mobile Mash-ups. Retrieved November 3, 2008, from http://paginaspersonales.deusto.es/dipina/ publications/SentientGraffitiAm107.pdf

Lugmayr, A., Risse, T., Stockleben, B., Kaario, J., \& Laurila, K. (2008). Semantic Ambient Media Expereinces SAME 2008 (NAMUSeries). Retrieved October 28, 2008, from Newell, A. F. (2008). Commentary on Computers and People with Disabilities: Accessible Computing - Past Trends and Future Suggestions. Transactions on Accessible Computing, 1(2), 9.1-9.7.

Punie, Y. (2003). A Social and Technological View of Ambient Intelligence in Everyday Life: What Bends the Trend? In Proceedings of the The European Media and Technology in Everyday Life Network, 2000-2003. Retrieved November 27, 2007, from www.lse.ac.uk/collections/EMTEL/reports/ punie_2003_emtel.pdf

Remagnino, P., \& Foresti, G. L. (2005). Ambient Intelligence: A New Multidisciplinary Paradigm. Transactions on Systems, Man and Cybernetics Part A . Systems and Humans, 35(1), 1-6.

Remagnino, P., \& Foresti, G. L. (2005). Ambient Intelligence: A New Multidisciplinary Paradigm. IEEE Transactions on Systems, Man, and Cybernetics. Part A, Systems and Humans, 35(1), 1-6. doi:10.1109/TSMCA.2004.838456

Schmidt, A. (2005). Interactive Context-Aware Systems Interacting with Ambient Intelligence. In Riva, G., Vatalaro, F., Davide, F., \& Alcaniz, M. (Eds.), Ambient Intelligence, The Evolution of Technology, Communication and Cognition, Towards the Future of Human-Computer Interaction (p. 164). Amsterdam: IOS Press.

Stanford Encyclopedia of Philosophy. (2009). Computer Information Ethics. Retrieved September 10, 2009, from http://plato.stanford.edu/entries/ ethics-computer 
Tham, Ng. A. (1998). Equality service accessible for all citizens, in particular elderly and disabled: TIDE.

van Loenen, E. J. (2003). On the role of Graspable Objects in the Ambient Intelligence Paradigm. In Proceedings of the Media Interaction Group, Philips Research Labs, Eindhoven, The Netherlands. Retrieved May 21, 2008, from http://www.minatec. com/grenoble-soc/proceedings03/Pdf/Van $\% 20$ Loenen.pdf
Warschauer, M. (2004). Technology and Social Inclusion (pp. 5-10). Cambridge, MA: MIT press. Retrieved from http://www./3s.de/web/upload/documents/1/SAME0820-lugmayr.pdf

Rosaleen Hegarty BSc (Hons) is a PhD student researching in the area of Ambient Intelligence in the School of Computing and Intelligent Systems, Faculty of Computing and Engineering at the University of Ulster, Magee College.

Tom Lunney BSc (Hons), MSc, P.G.C.E, PhD, MIEEE, MBCS received his degrees from Queen's University Belfast, and is now a Senior Lecturer in Computer Science in the University of Ulster. His research areas include concurrent and distributed systems, artificial intelligence and multi-modal computing. He has presented papers at a range of International Conferences and participated in the organising committees for a number of international conferences and workshops. He has taught at other educational institutions including Queens University, Belfast and The University of Pau, France. He is currently Course Director for postgraduate masters programmes in the University of Ulster.

Kevin Curran BSc (Hons), PhD, SMIEEE, MBCS CITP, MACM, MIEE, FHEA has made significant contributions to advancing the knowledge and understanding of computer networking, evidenced by over 400 publications. He is a regular contributor to BBC radio \& TV news in Northern Ireland and is listed in the Dictionary of International Biography, Marquis Who's Who in Science and Engineering and by Who's Who in the World. He has chaired sessions and participated in the organising committees for many highly-respected international conferences and workshops. He is the Editor in Chief of the International Journal of Ambient Computing and Intelligence and has served as an advisor to the British Computer Society in regard to computer industry standards.

Maurice Mulvenna received his degrees from the University of Ulster, where he is a senior lecturer in computer science. He researches artificial intelligence and pervasive computing and serves on many program committees, including IEEE Pervasive Computing, IEEE Pervasive Computing and Applications, Pervasive Systems and Computing and IEEE-ACM Web Intelligence. He is a senior member of both the IEEE and Association for Computing Machinery (ACM), and is a chartered member of the British Computer Society (BCS). 